\title{
Improving College Students' Success In Gateway Science Courses: Lessons Learned From An Anatomy And Physiology Workshop
}

Abass Abdullahi, City University of New York, USA Maureen Gannon, City University of New York, USA

\begin{abstract}
In this study, we evaluated the effectiveness of a two-week pre-anatomy and physiology workshop intended to contribute to student success in anatomy and physiology. The study showed that workshop participants had significantly higher post-test scores, better study habits, and generally felt more confident or prepared for anatomy and physiology. The workshop participants also reported that they understood membrane transport the least and organization of the body the most, information that may be useful in anatomy and physiology curriculum development. Preliminary studies also show that students that participated in the workshop performed significantly better than the general student body, with lower attrition rates in anatomy and physiology.
\end{abstract}

Keywords: Gateway Science Courses; Lessons Learned from an Anatomy and Physiology Workshop

\section{INTRODUCTION}

uman Anatomy and Physiology (A\&P) is a common gateway course in Allied Health careers, such as
Nursing. However, community college students perform poorly in this course, with a high number of
students earning grades D or F (Harris, Hannun \& Gupta 2004). The high failure rates in gateway courses often translates to fewer students reaching the level required to successfully progress in their elected program (Caon \& Treagust 1993).

Failure to succeed in gateway science courses is hardly surprising given the wide range of background that students enrolling in these courses have. Many students have weak general academic skills and little prior scientific knowledge prior to attempting the course (McKee 2002). Other students often do not see the relevance of gateway courses to their future careers (Thornton 1997; Jordan \& Reid 1997; Jordan, Davies \& Green 1999). As a result, there is so much anxiety among students enrolling in the course, with the general perception that it is a hard subject (Nicolel \& Butler 1996; Tronbranski 1993). This may affect student confidence and self-abilities, often leading to self-doubt among A\&P students, with the potential to negatively affect student performance (Hinds et al. 1999).

Unless measures are put in place to address these challenges, A\&P will continue to be a major obstacle for students interested in Allied Health careers. Student success in A\&P has been correlated with decreased external workload and better preparation (Harris et al. 2004). There are also studies showing some success utilizing electronic book activities (Raynor \& Iggulden 2008), Keller's Personalized System of Instruction (Fike et al. 2011) or in house online resources among others. However, our students have heavy outside workloads and remedial or pre-requisite courses in Biology to better prepare them, while desirable, are generally not offered, or if available not taken, due to a multitude of time and financial factors. 
In an attempt to address some of these issues, faculty in the Department of Biology at Bronx Community College of the City University of New York have developed and tested an intensive two-week pre-A\&P workshop that concentrates on providing students with basic concepts in the chemical and cellular level of organization. These areas are taught at the beginning of most two semester A\&P course sequences and failure to master these initial concepts is correlated with a higher withdrawal rate and lower passing grades that do not meet the required standard (Harris et al. 2004). Students were provided with interactive workbooks and practice quizzes that were developed specifically for underprepared students, using a pedagogical approach called LETME (Link, Extract, Transform, Monitor and Extend; Shenkman 2002). This technique provides a scaffolding approach similar to that used in Bloom's taxonomy, adjusted for high risk students.

This study aims to evaluate the effectiveness of this Pre-A\&P workshop on student attitudes and expectations prior to enrolling in A\&P and more importantly whether it improves their performance once enrolled. Specifically, the study attempts to answer the following research questions:

1. Does the workshop improve participants biology background on topics covered?

2. Does the workshop change their perceptions on the difficulty of topics covered?

3. Does the workshop change their perceptions on study aids?

4. $\quad$ Does the workshop change their expectations on Anatomy and Physiology?

5. Does the workshop improve their success in Anatomy and Physiology?

\section{METHODS}

Instructors facilitated intensive two week intersession workshops that immediately precede the first semester of the two semester A\&P sequence. A pedagogical technique called LETME (Link, Extract, Transform, Monitor, and Extend) was utilized during the workshop, where students were asked to make a connection between any prior knowledge to what was taught (Link); and choose relevant course information from workshop books and lectures (Extract). They learnt new concepts by applying appropriate methods such as taking notes, and group activities (Transform), and self evaluation of concepts mastery through pre- and post-daily quizzes (Monitor) and finally apply the knowledge to new concepts (Extend).

The workshop was run twice a year in the spring and summer from 2007 to 2011, except during 2008/2009 academic year (pre-fall 2008 and spring 2009), with eight independent groups completing it. It is noteworthy to mention that the first three independent groups (groups 1-3) comprised the general student population selected by lottery, whereas the next five groups (groups 4-8) were part of the HSA program. HSA students are preselected to participate in an enhanced pre-allied health sequence and were actively recruited and highly encouraged to attend the workshop. To the best of our knowledge, students who attended the workshop had, if necessary, passed, or were close to passing, any required remediation in English, Reading and Mathematics and had not previously attempted a college level A\&P or Biology course.

The following five topics were covered in the workshop: Organization of the Body - Structural Hierarchy of the Human Body \& Homeostasis, Atomic and Molecular Structure - Ionic, Covalent \& Hydrogen Bonding; Acids, Bases, \& Buffers, Metabolism - Types of Chemical Reactions, Functional Groups, Monomers \& Polymers, Macromolecules - Structure \& Function of Carbohydrates, Lipids, Proteins \& Nucleic Acids and Cell Membrane Structure \& Membrane Transport. Note that the topics have been shortened to the first bolded parts in the rest of the paper.

Pre- and post-tests and anonymous pre- and post-student surveys were administered to assess the effectiveness of the workshop. The pre- and post-tests data was collected for all eight groups (overall total of 201 students), but the surveys were only obtained from the spring and summer 2011 groups $(n=75)$. The surveys gauged student views on the difficulty of workshop topics using a Likert scale (very difficult to very easy on a scale of 1 to 5 respectively), helpfulness of workshop study aids (no help to great help on a scale of 1 to 5 respectively), and changes in post-workshop student expectations for the upcoming A\&P course. 
SPSS/PASW version 20 software was used for statistical analysis. Descriptive statistics was used to compare student pre- and post-workshop tests and surveys. Student paired t-test was used to find out whether there was significant differences between student pre- and post-workshop performance. Chi square test was used to test for significant difference between pre- and post-workshop surveys. Chi square analysis was also used to compare student satisfactory performance in A\&P I and II, defined as a grade of C+ or better, between workshop student participants and the general student population. Significance was set at $95 \%$ confidence level in all cases $(p<0.05)$.

\section{RESULTS}

\section{Student performance significantly improves in post-workshop tests}

Posttest scores, measured immediately after the last workshop session, were almost double pretest scores conducted at the beginning of the workshop (research question 1). Paired t-test analysis revealed that this difference between pre- and post-workshop tests was statistically significant for all eight independent groups (for example group 7 spring $11, \mathrm{t}(20)=8.52 ; \mathrm{p}=0.000)$. In fact, pre- and post-test scores were remarkably similar between workshops, with students' scores around 32-37\% at the beginning and 60-70\% at the end of the workshop (Figure 1). There were no significant differences in test scores between HSA students who were actively recruited to attend the workshop (Groups 4-8) and those who voluntarily attended the workshop (Groups 1-3, selected by lottery from all qualified students that applied to attend the workshop). It should be noted, however, that the total daily workshop hours in groups 1-3 were significantly longer. The main component eliminated from the workshop in Groups 4-8, due to budgetary constraints, was integrating student use of the textbook that accompanies the A\&P course into completing workbook activities i.e. students were not trained in how to navigate the text and did not have it as an additional resource when completing different activities. Concept coverage was not significantly altered between groups.

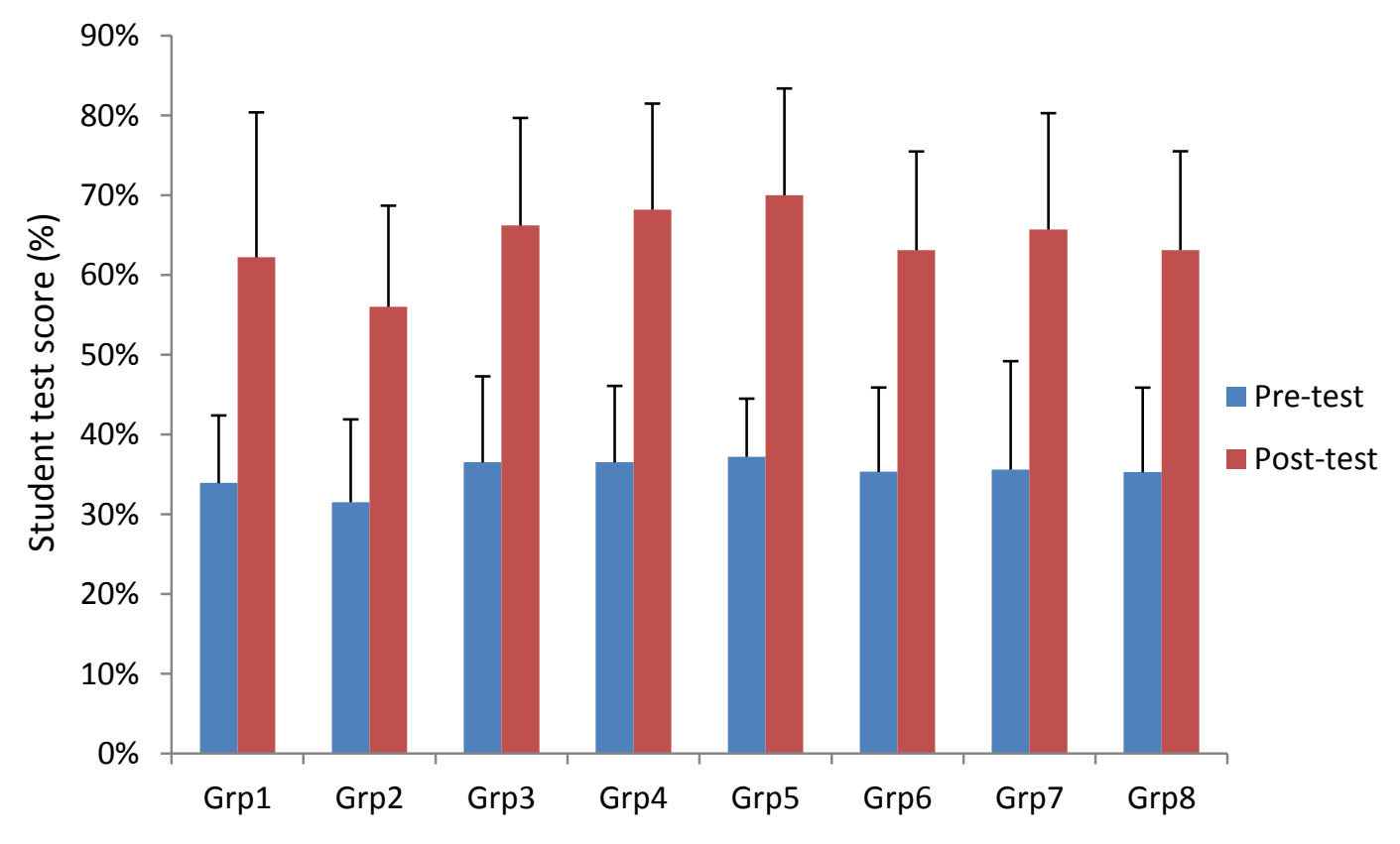

Figure 1: Pre-test and Post-test Scores from A\&P Workshops

Results shown are mean \pm standard deviation. Group 1 (SP07, $n=24)$, Group 2 (SU07, $n=16)$, Group 3 (SP08, $n=17)$, Group 4 (SU 09, n=16), Group $5(S P 10, n=10)$, Group $6(S U 10, n=43)$, Group $7(S P 11, n=21)$ and Group $8(S U 11, n=54)$. 


\section{Student ratings of difficulty of workshop topics changes between pre- and post-surveys}

Interestingly, student perceptions of the difficulty of topics changed between pre- and post-workshop surveys (research question 2). The average score given for each of the topics in Table 1 shows the numerical value for the Likert scale used. As an example, an average score of 3.06 on pre-workshop surveys indicates an overall student perception of "fair" on the Likert scale (1=very hard, $2=$ hard, $3=$ fair, $4=$ =asy, $5=$ =very easy) for the first workshop topic, organization of the body (Table 1). Indeed, more than half of the participants $(54 \%, n=72)$ chose that option (fair) and only $29 \%$ of pre workshop respondents felt this topic was easy or very easy (Figure 2). In contrast, $43 \%(\mathrm{n}=65)$ of post-workshop respondents selected fair, with $42 \%$ of this group choosing this topic to be easy or very easy. Chi square analysis showed that this difference in opinion between pre- and post-workshop surveys was statistically significant $\left(X^{2}(4,137)=14.99 ; p=0.005\right)$. Similarly, there were a significantly higher number of students that considered the topics, atomic \& molecular structure $\left(X^{2}(4,140)=12.30 ; p=0.015\right)$ and metabolism $\left(\mathrm{X}^{2}(4,137)=11.34 ; \mathrm{p}=0.023\right)$, to be relatively easier topics in post-workshop surveys compared to pre-surveys (Table 1).

However, there was no statistically significant difference in student opinions on the degree of difficulty of the other two topics, macromolecules $\left(\mathrm{X}^{2}(4,137)=8.56 ; \mathrm{p}=0.073\right)$ and cell membrane structures $\left(\mathrm{X}^{2}(4,134)=\right.$ $1.40 ; \mathrm{p}=0.844$ ) between pre- and post-workshop surveys. For instance, there were almost equal number of students that considered cell membrane structure to be hard or very hard (39\% in pre-workshop surveys versus $36 \%$ in postsurveys), fair (44\% versus $45 \%$ ) and easy or very easy (17\% versus $19 \%$ ).

Table 1: Students ratings of the 5 major topics covered in the workshop (very hard to very easy on a scale of 1 to 5 respectively)

Results shown are mean \pm standard error and p values to test for statistical significance (Chi square analysis). Note that the full description of the topics as given in methods is Organization of the Body - Structural Hierarchy of the Human Body \& Homeostasis, Atomic and Molecular Structure - Ionic, Covalent \& Hydrogen Bonding; Acids, Bases, \& Buffers, Metabolism - Types of Chemical Reactions, Functional Groups, Monomers \& Polymers, Macromolecules - Structure \& Function of Carbohydrates, Lipids, Proteins \& Nucleic Acids and Cell Membrane Structure \& Membrane Transport.

\begin{tabular}{lllr}
\hline Topic & Pre-survey; Mean \pm SE & Post-survey; Mean \pm SE & $3.40 \pm 0.11 ; \mathrm{n}=65$ \\
\hline Organization of the Body & $3.06 \pm 0.10 ; \mathrm{n}=72$ & $3.12 \pm 0.11 ; \mathrm{n}=65$ & 0.005 \\
Atomic and Molecular Structure & $2.69 \pm 0.10 ; \mathrm{n}=75$ & $3.03 \pm 0.09 ; \mathrm{n}=64$ & 0.015 \\
Metabolism & $2.59 \pm 0.12 ; \mathrm{n}=73$ & $2.91 \pm 0.10 ; \mathrm{n}=65$ & 0.023 \\
Macromolecules & $2.67 \pm 0.11 ; \mathrm{n}=72$ & $2.81 \pm 0.11 ; \mathrm{n}=64$ & 0.073 \\
Cell Membrane Structure & $2.71 \pm 0.11 ; \mathrm{n}=70$ & 0.844 \\
\hline
\end{tabular}

\section{Student perceptions on study aids changes from pre- to post-workshop surveys}

The mean rating for the helpfulness of the study aids is shown in Table 2 as the numerical value for the Likert scale ( $1=$ No help, $2=$ a little help, $3=$ moderate help, $4=$ much help, $5=$ great help). An average rating of 3.43 for the helpfulness of paying attention in class in pre-workshop surveys shows an overall student perception that approximates moderate help (Table 2). This perception was significantly different in post-workshop surveys (research question 3), where the mean rating of 4.11, indicates that paying attention in class was of much help $\left(\mathrm{X}^{2}\right.$ $(4,132)=25.64 ; \mathrm{p}=0.001)$. A third $(34 \%, \mathrm{n}=70)$ of the students felt that paying attention in class was of no help or a little help in pre-workshop surveys compared to 5\% in post-surveys, with more students (79\% versus 60\%) stating that it was of much help or great help after the workshop (Figure 3). There were also significantly higher number of students that considered participating in discussions during class $\left(X^{2}(4,131)=16.06 ; p=0.003\right)$ and practicing test questions in and out of class $\left(\mathrm{X}^{2}(4,127)=13.99 ; \mathrm{p}=0.007\right)$ to be relatively more helpful in post-workshop surveys compared to pre-workshop surveys (Table 2). 


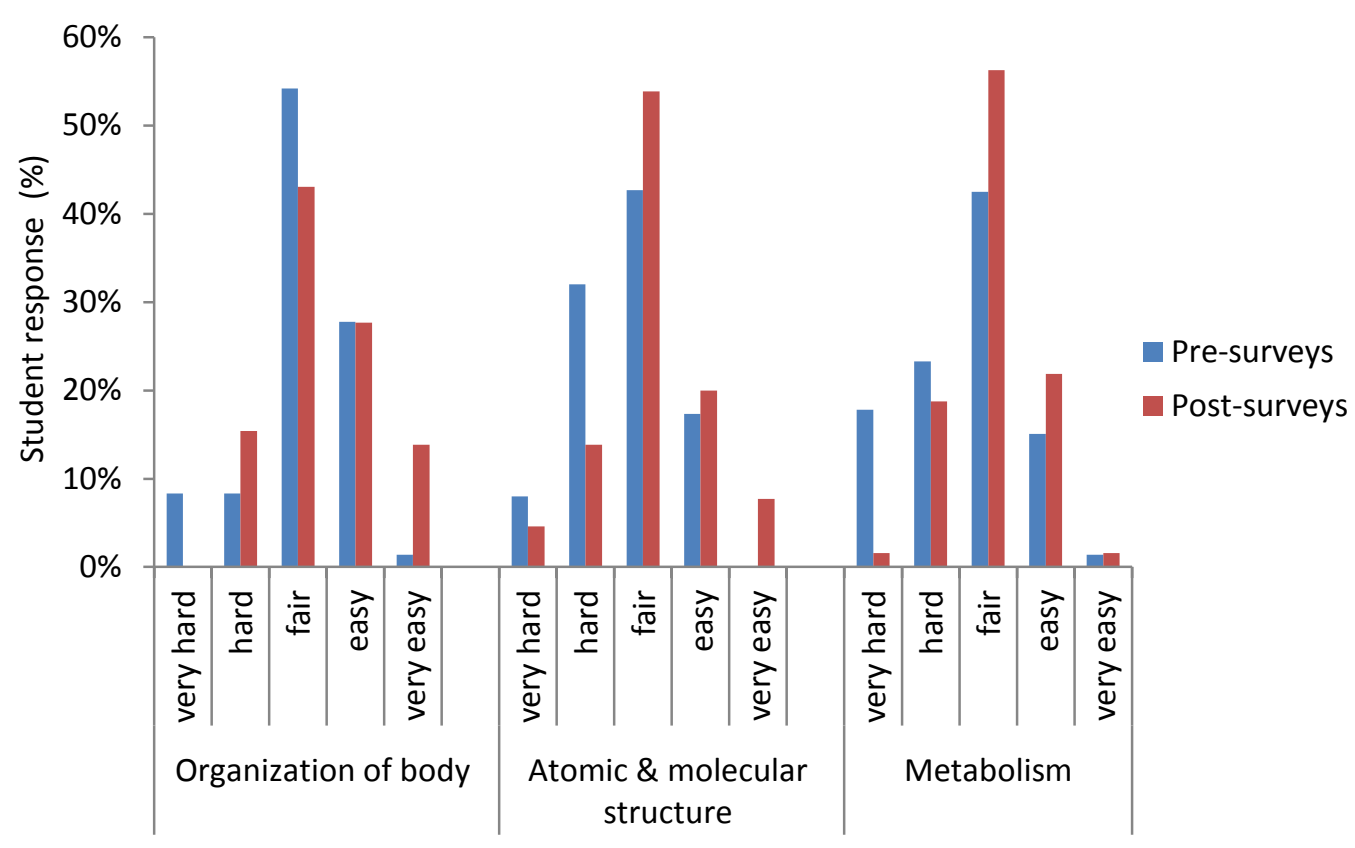

Figure 2: Students rating details of the 3 major topics that had significant differences in opinion between pre- and post-workshop surveys

Note that sample sizes (n) and full descriptions of workshop topics are the same as that given in Table 1.

An equal number of students (30\%) felt that working with peers in study groups was of no help or a little help in pre- and post-surveys. Although there were more students that perceived peer study groups to be of moderate help (28\% versus $17 \%$ ) in post-workshop surveys, this was offset by fewer students considering it to be of much help or great help (43\% versus 53\%) compared to pre-workshop surveys. As a result, chi square analysis showed that there were no significant differences in pre- and post-workshop student opinions regarding the helpfulness of working with peers in study groups $\left(X^{2}(4,124)=4.75 ; p=0.314\right)$. Interestingly, the mean number of students that considered studying outside of class to be helpful dropped from 3.60 in pre-workshop surveys to 3.44 in post-surveys, with the difference statistically significant $\left(X^{2}(4,131)=17.74 ; p=0.001\right)$. This significant difference, however, may be explained by the fact that student opinions were on either extremes (30\% for no help/a little help and $60 \%$ for much help/great help) during pre-workshop surveys. In contrast, the responses were more evenly distributed in post-surveys, with $23 \%$ of students considering it to be of no help or a little help, $30 \%$ moderate help and $48 \%$ of much help or great help.

Table 2: Student's ratings of the helpfulness of study aids Results shown are mean \pm standard error of mean and $p$ values to test for statistical significance (Chi square analysis)

\begin{tabular}{llll}
\hline Helpfulness of study aids & Pre-survey; Mean \pm SE & Post-survey; Mean \pm SE & p value \\
\hline Paying attention in class & $3.43 \pm 0.21 ; \mathrm{n}=70$ & $4.11 \pm 0.13 ; \mathrm{n}=62$ & 0.001 \\
Participating in discussions during class & $3.11 \pm 0.19 ; \mathrm{n}=70$ & $3.93 \pm 0.14 ; \mathrm{n}=61$ & 0.003 \\
Practicing test questions in and out of class & $3.48 \pm 0.19 ; \mathrm{n}=69$ & $4.05 \pm 0.13 ; \mathrm{n}=58$ & 0.007 \\
Studying outside of class & $3.60 \pm 0.19 ; \mathrm{n}=70$ & $3.44 \pm 0.15 ; \mathrm{n}=61$ & 0.001 \\
Working with peers in study groups & $3.27 \pm 0.19 ; \mathrm{n}=70$ & $3.11 \pm 0.19 ; \mathrm{n}=54$ & 0.314 \\
\hline
\end{tabular}




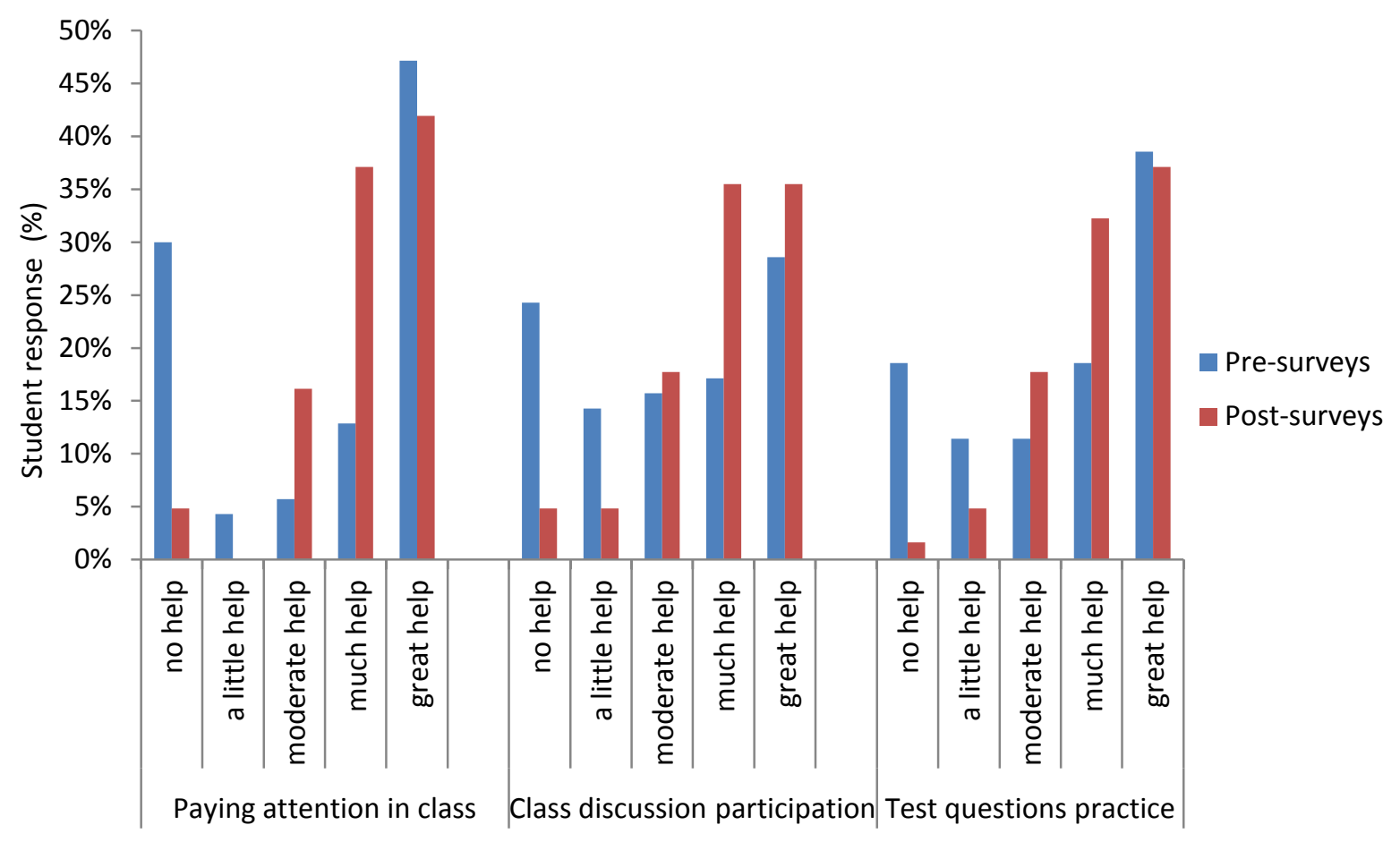

Figure 3: Students rating details of the 3 most helpful study aids in post-workshop surveys relative to pre-workshop surveys Note that sample sizes ( $n$ ) are the same as that given in Table 2.

\section{Three quarter of students changed their expectations on Anatomy and Physiology}

Most students indicated that they were interested in a career in nursing and were attending the workshop to be better prepared for A\&P, in response to an open ended pre-workshop survey question "please tell us why you are attending this workshop and your career goals." Some of the student responses include:

"To gain a better understanding of what will be required when the actual course takes effect. My career goals are to become a registered nurse."

"I want to be able to obtain a good grade in class and to refresh my memory on the subject."

"I am a nursing major who is struggling with science...I have been out of school for 16 years...am grateful they are offering such workshop." Others had extra motivations for taking the workshop "I don't want a minimum wage job. I want to be financially stable by at least 26. I also want to set an example for my daughter."

An overwhelming majority of participants answered Yes $(72 \%, \mathrm{n}=50)$, when asked the question "Did this workshop change your expectations about how Anatomy and Physiology I is going to be?" (research question 4). This indicated that the workshop had a major influence on student opinions on A\&P. To further find out student views on the workshop and A\&P in general, they were asked an open ended question to explain their YES or NO answer. Students that answered YES were in the following categories:

A) Those that became confident they could succeed in Anatomy and Physiology (about 38\% of YES respondents that commented)

Examples "Now that I see how the work is going to be, I know that I can do it and I know what to do and what not to do."

"I thought the course was going to be tougher than this based on what people told me, but I think by paying attention in class and studying on my own and also working with peers, am going to sail through." 
"I was initially thinking that the course is something that I cannot do. However that perception has changed, I need hard work."

"I thought it was going to be an extremely difficult class and after this workshop, I feel comfortable with the course. All the material reviewed has gotten me more interested in the class."

B) Those surprised at how much time and effort was needed to succeed in Anatomy and Physiology (about $31 \%$ of YES respondents that commented)

Examples "I realize now Anatomy and Physiology will be much more difficult than I originally thought."

"I thought it was going to be easier, but this workshop showed me otherwise."

"I didn't think this course was going to be this intense and tough."

"I thought this class would be a piece of cake. I know now that I will have to study and read a lot in order to get the best possible grade that I can achieve."

"Now I know that I need to study both at home and in school."

C) Those that felt they now knew what the course is about, without commenting on confidence or effort required (about $21 \%$ of YES respondents that commented)

Examples "Yes, because I was so confused about how the whole course was going to be like."

"It gave me a sense of how the real Anatomy and Physiology course is going to be."

"It helped me prepare for the course."

D) Those surprised at how much Chemistry was in a Biology (Anatomy and Physiology) course (about $10 \%$ of YES respondents that commented)

Examples "It is not until I took this workshop that I realized how many different things compose biology even chemistry, charges etc."

In contrast, the few students that indicated the workshop didn't change their expectations on A\&P were all in one category:

A) Those that already knew Anatomy and Physiology as a difficult subject.

"No, I already knew it would be hard."

"I still believe this class is going to be very hard."

"The class is hard and is what I felt it was going to be, but now I will be better prepared."

"I knew coming in that biology is a very difficult topic that requires a lot of studies, concentration as well as discipline to be successful."

\section{Workshop participants have better satisfactory performance in A\&P than regular students}

Finally, the study showed that workshop participants were more likely to earn satisfactory performance (defined as a grade of C+ or better grades) in A\&P I and II courses compared to the general student population (research question 5). It is worth noting, however, that this data was only collected for workshop participants that were part of the HSA program (groups 4-7 in Figure 1, data not yet collected for HSA group 8). About 51\% of HSA students (n=97) earned $\mathrm{C}+$ or better grades in A\&P I compared to $36 \%$ of regular students ( $=1429$, Figure 4), a difference that was statistically significant $\left(\mathrm{X}^{2}(1,1525)=7.17 ; \mathrm{p}=0.007\right)$. Chi square analysis showed the difference was even more significant in A\&P II, where $85 \%$ of HSA students $(n=62)$ earned $C+$ or better compared to $48 \%$ of the general student $(n=491)$ population $\left(\mathrm{X}^{2}(4,552)=12.29 ; \mathrm{p}=0.000\right)$. This data needs to be interpreted cautiously though due to the small sample size for workshop participants relative to the general student body. 


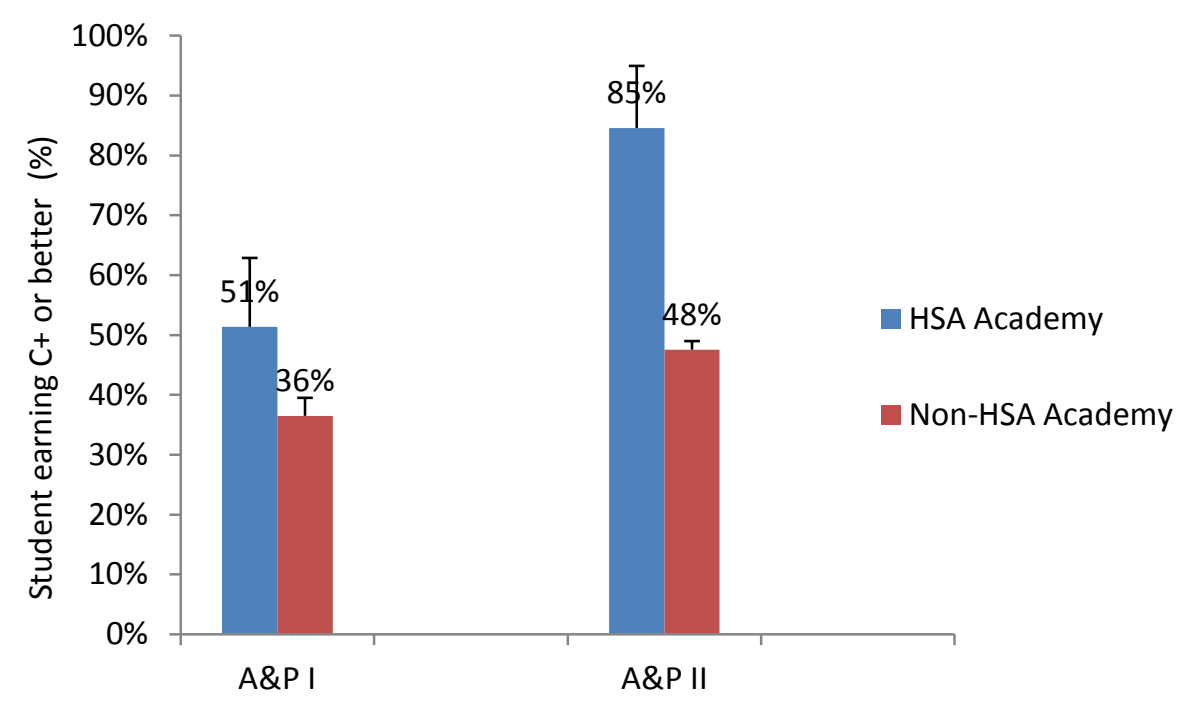

Figure 4: Comparison of HSA students (workshop participants)

and non-HSA students' satisfactory performance (C+ or better grade) in Anatomy and Physiology I and II

Results shown are mean \pm standard deviation for 2008/2009, 2009/2010 and 2010/2011. HSA sample size was low at $n=97$ for A\&P I and $n=62$ for $A \& P I$, but samples sizes were higher for non-HSA at $n=1429$ and 491 respectively).

\section{DISCUSSION}

To the best of our knowledge, workshop participants had not previously attempted a college level A\&P or Biology course. The workshop thus attempted to provide students with both effective study strategies and relevant orientation to content knowledge prior to attempting the rigors of A\&P. Pretest scores demonstrated that students had little prior concept knowledge immediately available to them at the start of the workshop, an observation confirmed by informal student surveys conducted immediately after the pretest.

Interestingly, students required to participate in the pre-workshop, as part of a HSA program (groups 4-8), and those that voluntarily participated in the workshop (groups $1-3)$ had remarkably similar pretest (36 $\pm 11 \%$ versus $34 \pm 10 \%)$ and posttest scores $(66 \pm 14 \%$ versus $62 \pm 15 \%$ respectively). Posttest scores were almost double the pretest scores in both groups, indicating that participants gained some theoretical knowledge, which may be useful once they enroll in A\&P. Since both groups met similar academic requirements, this suggests that the posttest results reflect the workshop itself, and not variations attributable to student motivation.

An intensive summer study course for pre-college students just before starting their course has shown improvements in student performance (Rutishauser et al. 1985). Preliminary analysis of the effect of workshop participation on subsequent student performance in $\mathrm{A} \& \mathrm{P}$ is also very encouraging in our case. Workshop participants show a marked improvement in student performance in A\&P, with higher overall passing rate (51\% versus $36 \%$ in $\mathrm{A} \& \mathrm{P}$ I and $85 \%$ versus $48 \%$ in A\&P II) and a higher percentage of students meeting the required standard. There is also a lower withdrawal rate among workshop participants taking A\&P (data not shown). We are currently attempting to determine whether this improvement is related to workshop attendance alone, or influenced by additional variables inherent to the general student body. Furthermore, we are also determining the relationship, if any, of post-test workshop scores to performance in the A\&P sequence.

In this study, in addition to test scores, student perceptions of study aids, difficulty of workshop topics, and expectations of A\&P were significantly different between pre- and post-workshop surveys. Students' rated paying attention in class highly, especially in post-workshop surveys. Participating in class discussions and practicing test questions were also rated more favorably after students attended the workshop. This suggests that the workshop may have had a positive influence on study skills, by enabling them to identify most helpful study habits. Poor 
study habits have been correlated with poor performance in the biological sciences (McKee 2002) and previous theoretical background in the biological sciences and better study skills have been correlated with success (Jordan et al. 1999; Rutishauser et al. 1985). It is likely that the concepts and study skills acquired in the workshop are committed to memory and transferred to subsequent coursework, partly accounting for workshop participants' better A\&P performance.

However, the surveys also indicated that a significant number of the students reported that studying outside of the workshop was of little or moderate help. Sadly, this is presumably because the majority also reported that they studied less than four hours a week outside of the workshop, with many studying less than two hours (data not shown). Hopefully, this does not mean that workshop participants believe they can gain the required level of competency in A\&P with minimal independent study. Instructors' stressed that the time spent reinforcing and practicing different concepts during the workshop was more than twice that spent during the A\&P course and that they should employ similar study skills outside of the classroom. Successful students are aware of, plan time for and utilize effective independent study strategies (Harris et al. 2004). However, despite the failure of workshop students to independently study outside of the workshop, the improvement between pre- and post-test scores clearly demonstrates that they have the academic potential to succeed in A\&P.

This improved post-test performance may have been influential in changing student expectations on A\&P, with a number of students indicating that they were more confident to take the class in post-workshop surveys. Increased student confidence in their ability will most likely minimize self-doubt and unnecessary exam tensions that have often been linked to poor performance (Hinds 1999). Students were also more likely to rate topics as relatively "easier" in post-workshop surveys than in pre-surveys, also implying more confidence. However, some students had also changed expectations after workshop participation enabled them to realize that A\&P required more effort, or incorporated more chemistry, than they thought. The workshop may have been very useful for these students to identify specific concept areas that are harder to master. In agreement with the instructors' impressions of the student difficulties with learning specific concepts, students perceived cell membrane transport and macromolecules as the most challenging topics, whereas they felt organization of the body was relatively easier. It is reasonable to expect that this may be useful in enabling these students to better plan for A\&P. This is also valuable information in planning the timing and depth of concept coverage during the A\&P course sequence.

As a result of the workshop, our department has integrated as many student-centered interactive activities into our A\&P curriculum as practically possible. While students that voluntarily attend concurrent tutoring, study laboratories or review sessions outperform their peers in A\&P (personal observations), the availability and utilization of such resources is usually limited by both college resources and the student's motivation or ability to find the time to attend. We will also continue to improve the workshop, with the goal of applying the most helpful approaches for students' success in A\&P. The workshop may even provide us with a relatively cheap screening tool that could be used during advisement to direct students into appropriate career pathways.

\section{CONCLUSION}

In summary, offering the pre-A\&P workshop in its current format, seems to be a cost effective way to increase student success in A\&P. The workshop can be given in a two week intensive format during intersession, consistently results in increased learning, and appears to increase the probability of student success in A\&P. We predict that attending the workshop will increase student progression and retention in Allied Health programs and result in a more productive use of limited college resources. The concept of an intensive intersession workshop, tailored to the academic level of the 'at risk' student, should be easily applicable to any field of study that has a specialized content area.

\section{ACKNOWLEDGMENTS}

The authors acknowledge the significant contributions of fellow departmental faculty members, Seher Atamturktur, Carlos Liachovitsky and Shylaja Akkaraju in the compilation of the pre-A\&P workbook and the helpful assistance of Dr. John Davis. Workshops were supported, in part, by funds from a Perkins grant to BCC. 


\section{AUTHOR INFORMATION}

Dr. Abass Abdullahi is an Assistant professor at Bronx Community College of the City University of New York and a Research Assistant professor at City College of the City University of New York. He has an interest in Biomedical, allied health and public health as well as pedagogical research including distance learning, assessment and teaching with technology. E-mail: Abass.Abdullahi@bcc.cuny.edu. Corresponding author.

Dr. Maureen Gannon is an Associate professor at Bronx Community College of the City University of New York, with research interests in allied health student success and pedagogy. She often uses her previous work in a nursing school in her classes and is actively involved in departmental assessment. E-mail: maureen.gannon @ bcc.cuny.edu

\section{REFERENCES}

1. Caon, M \& Treagust, D. (1993). Why do some nursing students find their science courses difficult? J. Nurse Ed. 32(6), 255-259.

2. $\quad$ Fike, D.S., Raehl, C.L., McCall, K.L., Burgoon, S.C., Schwarzlose, S.J., \& Lockman, P.R. (2011). Improving Community College Student Learning Outcomes in Biology. Electronic Journal of Science Education. 15 (1), 1-12.

3. Harris, D.E., Hannum, L., \& Gupta, S (2004). Contributing factors to student success in Anatomy and Physiology: Lower outside workload and better preparation. American Biology Teacher. 66 (3), 168-175.

4. Hinds, I.L. (1999). Special needs of adult learners in science (Biology). Community Review, 17, 42-48.

5. Jordan, S., Davies, S., and Green, B. (1999). The biophysical sciences in the pre-registration nursing curriculum: staff and students' perceptions of difficulties and relevance. Nurse Ed. Today. 19, 215-226.

6. Jordan, S. \& Reid, K. The biological sciences in nursing: an empirical paper reporting on the application of physiology to nursing care. Journal of Advanced Nursing 1997, 26, 169-79.

7. McKee, G. (2002). Why is biological science difficult for the first-year nursing students? Nurse Ed. Today. 22, 251-257.

8. Nicolel, L. \& Butler M. The study of biology as a cause of anxiety in student nurses undertaking the common foundation programme. Journal of Advanced Nursing 1996, 24, 615-24.

9. Raynor, M. \& Iggulden, H. (2008). Online anatomy and physiology: piloting the use of an anatomy and physiology e-book-VLE hybrid in pre-registration and post-qualifying nursing programmes at the University of Salford. Health Information and Libraries Journal. 25, 98-105.

10. Rutishauser, S. \& Stephenson, P. (1985). The feasibility of students with a predominantly arts educational background coping with the physiology component of a university degree programme. Journal of Advanced Nursing: 10: 559-566.

11. Shenkman, H.L. (2002). Reading, learning, and thinking seminars: A template for faculty training. Learning Abstracts, 5(1).

12. Thornton, $\mathrm{T}$ (1997). Attitudes towards the relevance of biological, behavioural and social sciences in nursing education. J. Ad. Nursing. 26, 180-186.

13. Tronbranski, P. Biological sciences and the nursing curriculum: a challenge for educationalists. Journal of Advanced Nursing 1993, 18, 493-9. 